
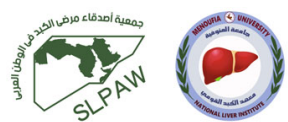

\title{
Evaluation of long-term changes of aspartate-platelet ratio index, FIB4, and liver stiffness in chronic hepatitis $C$ patients successfully treated by direct-acting antivirals
}

Nadia Abdel Ataay Abdelkader', Osama Ashraf Ahmed², Ahmed Fouad Sherief', Doaa Mahmoud Kandil', Mohammed Soliman Gado ${ }^{1}$ and Amira Mahmoud Al Balakosy ${ }^{1 *}$ (i)

\begin{abstract}
Background: A large number of chronic hepatitis $C$ patients had been successfully treated by directly acting antivirals; therefore, strategies for the long-term follow-up of these patients have to be planned based on the posttreatment fibrosis stage - the main determinant of prognosis. In this study, we aim to evaluate changes in aspartate-platelet ratio index, FIB4, and liver stiffness in chronic hepatitis C patients who achieved SVR and ended treatment more than 1 year by DAAs.

Results: One hundred chronic hepatitis C patients who achieved SVR were enrolled at a median of 16 months after the end of treatment by DAAs. According to the baseline liver stiffness, 63 and 37 patients belonged to early (F0, F1, and F2) and advanced (F3 and F4) fibrosis stages, respectively. Both groups showed a decline of the degree of liver stiffness at follow-up compared to the baseline that was statistically significant in the early fibrosis group (5.9 \pm 1.5 vs $5.4 \pm 2.2 \mathrm{Kpcal}, p=0.04)$, while measurements in the advanced group were $(18 \pm 8.8$ vs $15.9 \pm 7.8 \mathrm{Kpcal}, p=0.07)$. Also, serum biomarkers of fibrosis improved in both groups, where the recorded APRI and FIB4 before and after treatment were $0.42 \pm 0.3$ vs $0.24 \pm 0.1, p<0.01$ and $1 \pm 0.6$ vs $0.93 \pm 0.5, p=0.1$ in the early group and $0.85 \pm 0.5$ vs $0.4 \pm$ $0.2, p<0.001$ and $2.9 \pm 2.3$ vs $1.8 \pm 1.4, p<0.02)$ in the advanced group, respectively. Changes in APRI and FIB4 correlated with changes in AST and ALT, but liver stiffness changes were not affected by changes in liver enzymes.

Conclusion: Although long-term improvement of APRI, FIB4, and liver stiffness scores could be achieved in chronic HCV patients after SVR by DAAS. High measurements of liver stiffness before treatment likely persist. We recommend transient elastography as a reliable tool for fibrosis assessment post-treatment.
\end{abstract}

Keywords: Liver stiffness, APRI, FIB4, Chronic HCV, DAAS, SVR, Long-term

\footnotetext{
*Correspondence: drbalakosy@gmail.com

${ }^{1}$ Tropical Medicine Department, Faculty of Medicine, Ain Shams University,

38 Abbassia street, Postal code, Cairo 1181, Egypt

Full list of author information is available at the end of the article
}

\section{Springer Open}

( ) The Author(s). 2021 Open Access This article is licensed under a Creative Commons Attribution 4.0 International License, which permits use, sharing, adaptation, distribution and reproduction in any medium or format, as long as you give appropriate credit to the original author(s) and the source, provide a link to the Creative Commons licence, and indicate if changes were made. The images or other third party material in this article are included in the article's Creative Commons licence, unless indicated otherwise in a credit line to the material. If material is not included in the article's Creative Commons licence and your intended use is not permitted by statutory regulation or exceeds the permitted use, you will need to obtain permission directly from the copyright holder. To view a copy of this licence, visit http://creativecommons.org/licenses/by/4.0/. 


\section{Background}

Hepatitis $\mathrm{C}$ virus (HCV) chronic infection is an important etiology of chronic liver disease that is prevalent worldwide; therefore, discovering an effective antiviral therapy was a major target for research [1]. Additionally, chronic $\mathrm{HCV}$ is considered the main risk factor for cirrhosis and development of hepatocellular carcinoma [2].

The introduction of direct-acting antiviral drugs (DAAs) was a revolution in HCV management with great safety and efficacy profile. Also, successful treatment of HCV decreases cirrhosis-related complications [3]. Many studies discussed the possibility of fibrosis regression following sustained virological response (SVR) achievement by DAAs which is debatable [4].

Chronic $\mathrm{HCV}$ infection and the resultant hepatocyte injury induce an inflammatory response that produces cytokines leading to stimulation of hepatic stellate cells (HSC) and fibrogenesis initiation, and elimination of the injurious agent would halt this inflammatory process. At later stages, fibrosis regression would depend on apoptosis of activated HSC and degradation of the extracellular matrix which is affected by the duration and components of the scar tissue [5].

$\mathrm{CHCV}$ patients with advanced liver fibrosis are at risk of developing hepatocellularcarcinoma (HCC), despite HCV eradication [6]. So the determination of the liver fibrosis stage after treatment is essential to detect the patients' need for continuous surveillance [7].

Liver biopsy is the gold standard for the evaluation of the degree of tissue damage and hepatic fibrosis. Due to its limitations and procedure-related complications, the use of non-invasive methods for fibrosis assessment has become an alternative. Among the most widely used and validated are serum biomarkers and transient elastography. Aspartate to platelet ratio index (APRI) and fibrosis-4-index (FIB4) are serum biomarkers that have high applicability and reproducibility being calculated by using routine laboratory indices. While transient elastography (TE) physically assessed liver fibrosis by measuring liver stiffness with the advantages of being reliable, safe, and easy to perform [8].

In Egypt, the National Committee for Control of Viral Hepatitis (NCCVH) implemented a national strategy aiming to eradicate $\mathrm{HCV}$, and this target became feasible by the availability of DAAs since 2014. Initially, patients with advanced fibrosis stages were only included in the treatment program, but later in 2015, all fibrosis stages (F0-F4) received antiviral therapy without discrimination [9]. By 2018, 40\% of the total HCV-infected population (2 million patients) were treated by DAAS with SVR above $90 \%$ [10]. So, a strategy for the follow-up of this large number of cured patients has to be planned to put into consideration patients with utmost priority. In the current study, we aim to share our center experience in the follow-up of successfully treated $\mathrm{CHCV}$ patients as regards the changes in scores of non-invasive tests of fibrosis APRI, FIB4, and TE.

\section{Methods}

This is a single-center retrospective and prospective cohort study, which was conducted at the Viral Hepatitis Treatment Unit, Ain Shams University Hospitals, during the time period from October 2017 to December 2018. Chronic HCV patients who ended treatment with DAAS and attended at our outpatient clinic for follow-up were included if fulfilling the following criteria:

1. Chronic HCV patients who were treated with a complete course of all oral DAAS regimens, achieved SVR and at least 1 year has passed since the end of treatment.

2. Patients who had baseline transient elastography (TE) done before DAAS initiation.

3. Complete data available in files.

\section{Exclusion criteria}

Patients who developed ascites and/or HCC at the time of follow-up.

The following workup was done for re-evaluation of included patients:

1. Clinical assessment for symptoms or signs of liver cell failure and laboratory investigations as CBC, AST, ALT, total and direct bilirubin, and albumin and INR.

2. Liver stiffness measurement (LSM) using TE: The device used is FibroScan ${ }^{\oplus}$ (Echosens, Paris, France). The operator placed the transducer in the intercostal space at the mid-axillary line in the right hypochondrium and took at least 10 measurements. An interquartile range of $\leq 30 \%$ and a success rate of $>80 \%$ were required for a valid interpretation [8].

TE results were correlated to different stages of liver fibrosis according to the histological staging system of METAVIR (Table 1) [11].

\section{Non-invasive serum fibrosis biomarkers}

Aspartate aminotransferase-to-platelet ratio index (APRI) and fibrosis-4 index (FIB-4) were calculated at baseline and at follow-up by using the following equations:

1. APRI score by Wai's formula [12]: (AST/upper limit of normal)/platelet count (expressed as platelets $\times 109 / \mathrm{L}) \times 100$ 
Table 1 Histological staging system of METAVIR

\begin{tabular}{lll}
\hline Stage & Metavir Scoring System & Fibroscan cut-off values (Kpcal) \\
\hline \hline F0 & No fibrosis & $0-5.4$ \\
F1 & Portal fibrosis without septa & $5.5-6.9$ \\
F2 & Portal fibrosis with few septa & $7-9.4$ \\
F3 & Numerous septa without cirrhosis & $9.5-12.4$ \\
F4 & Cirrhosis & 12.5 \\
\hline
\end{tabular}

2. FIB-4 score by Sterling's formula [13] : Age (years) $\times \operatorname{AST}(\mathrm{IU} / \mathrm{L}) /$ platelet count $(\times 109 / \mathrm{L}) \times \sqrt{\mathrm{ALT}}(\mathrm{IU} /$ L)).

\section{Statistical analysis}

The collected data was revised, coded, tabulated, and introduced to a computer using Statistical package for Social Science (SPSS 20). Parametric numerical data was presented as mean, standard deviation $( \pm S D)$, and range while non-parametric numeric data were presented as the median and interquartile range (IQR). Non-numeric data were presented as the frequency and percentage.

We used Student $T$ test to compare two paired study group means. Pearson correlation $(r)$ was used for measuring a linear dependence between two variables. The McNemar test is used to analyze pretest-posttest fibrosis study groups. Regression analysis was used for estimating the relationships between baseline factors and changes in LSM. Repeated-measures ANOVA was used to compare the changes of LSM across time between the early and advanced fibrosis group.

\section{Results}

During the time period from October 2017 to December 2018, 120 chronic HCV patients attended our clinic for follow-up after the end of treatment with DAAs, only 100 patients fulfilled the inclusion criteria and were enrolled in this study while 20 patients were excluded, as 2 were relapsers, 7 developed $\mathrm{HCC}$ and/or ascites while 11 patients refused to participate.

Among the included patients, 63 belonged to early fibrosis stages (F0, F1, and F2), while 37 patients belonged to advanced stages (F3 and F4) classified according to baseline TE readings retrieved from patients' files.

The median duration since the end of treatment in included patients was 16 months (minimum and maximum-12 and 33 months, respectively), where most of the patients (75th percentile) were re-examined at 21 months after the end of treatment.

\section{Baseline patient characteristics}

The mean age of included patients was $48+15$ years: 52 males and 48 females. Diabetes and hypertension were reported in 14 and 12 patients, respectively (Table 2).
The mean LSM of patients in the early fibrosis stage was $5.9 \pm 1.5 \mathrm{Kpcal}$ while that of the advanced stage was $18 \pm$ 8.8 Kpcal (Table 3).

Before treatment initiation, the median of HCV RNA quantitative was $2066.45(\mathrm{IQR}=4000)$, SVR was confirmed by undetectable $\mathrm{HCV}$ PCR at week 12 posttreatment in all included patients. Treatment regimens used were Sofosbuvir/Dacltasvir for 12 weeks in 58 patients; most of them $(n=51)$ were at early fibrosis stages, while 32 patients including 18 with advanced fibrosis received Sofosbuvir/Dacltasvir/Ribavirin for 12-24 weeks; finally, only 10 patients were treated by PAR/OMB/RBV; and most of them belonged to F0.

Table 2 Baseline patients' characteristics

\begin{tabular}{|c|c|}
\hline Age (years) & $48 \pm 15$ \\
\hline BMI & $26 \pm 3.7$ \\
\hline Female (\%) & 48 \\
\hline Male (\%) & 52 \\
\hline Diabetes (\%) & 14 \\
\hline Hypertension (\%) & 12 \\
\hline Other co-morbidities*(\%) & 11 \\
\hline HCV RNA quantitative ${ }^{*}$ & $2066.45 \pm 4000$ \\
\hline ALT (IU/L) & $53.5 \pm 40$ \\
\hline AST (IU/L) & $48 \pm 29$ \\
\hline AFP (IU/L) & $4.3 \pm 3.4$ \\
\hline Albumin (g/dL) & $4.1 \pm 0.5$ \\
\hline Total bilirubin (mg/dL) & $0.75 \pm 0.4$ \\
\hline Indirect bilirubin (mg/dL) & $0.48 \pm 0.4$ \\
\hline $\mathrm{WBC} \times 10^{3} / \mathrm{mm}^{3}$ & $7.1 \pm 2.2$ \\
\hline $\mathrm{Hb}(g / d L)$ & $13.5 \pm 1.8$ \\
\hline Creatinine (mg/dL) & $0.9 \pm 0.2$ \\
\hline INR & $1.1 \pm 0.1$ \\
\hline Platelets $\times 10^{3} / \mathrm{mm}^{3}$ & $231.7 \pm 72$ \\
\hline \multirow[t]{5}{*}{ Fibrosis stage (F) by TE (\%) } & F0 (23\%) \\
\hline & F1 $(26 \%)$ \\
\hline & F2 (14\%) \\
\hline & F3 (9\%) \\
\hline & F4 (28\%) \\
\hline
\end{tabular}

*Ischemic heart diseases and bronchial asthma 
Table 3 Laboratory and fibrosis score changes in early and advanced groups

\begin{tabular}{|c|c|c|c|c|c|c|}
\hline & Early stage & & & Advancec & & \\
\hline & Baseline & Follow-up & $P$ value & Baseline & Follow-up & $P$ value \\
\hline Stiffness & $5.9 \pm 1.5$ & $5.4 \pm 2.2$ & 0.04 & $18 \pm 8.8$ & $15.9 \pm 7.8$ & 0.077 \\
\hline APRI score & $0.42 \pm 0.3$ & $0.24 \pm 0.1$ & $<0.01$ & $0.85 \pm 0.5$ & $0.4 \pm 0.2$ & $<0.001$ \\
\hline Fib4 & $1 \pm 0.6$ & $0.93 \pm 0.5$ & 0.1 & $2.9 \pm 2.3$ & $1.8 \pm 1.4$ & 0.002 \\
\hline $\mathrm{ALT}(\mathrm{IU} / \mathrm{L})$ & $53 \pm 42$ & $21 \pm 10$ & $<0.01$ & $55 \pm 37$ & $26 \pm 11$ & $<0.001$ \\
\hline AST (IU/L) & $42 \pm 30$ & $24 \pm 10$ & $<0.01$ & $58 \pm 26$ & $28 \pm 11$ & $<0.001$ \\
\hline AFP (IU/L) & $3.3 \pm 2$ & $3.5 \pm 1.8$ & 0.5 & $6 \pm 4.2$ & $5.5 \pm 3$ & 0.4 \\
\hline Albumin (g/dL) & $4.2 \pm 0.35$ & $4.1 \pm 0.3$ & 0.35 & $3.9 \pm 0.6$ & $3.9 \pm 0.4$ & 0.5 \\
\hline Total bilirubin (mg/dL) & $0.6 \pm 0.2$ & $0.7 \pm 0.2$ & 0.2 & $0.9 \pm 0.5$ & $0.86 \pm 0.3$ & 0.4 \\
\hline Indirect bilirubin (mg/dL) & $0.4 \pm 0.4$ & $0.4 \pm 0.2$ & 0.7 & $0.6 \pm 0.3$ & $0.5 \pm 0.2$ & 0.5 \\
\hline $\mathrm{WBC} \times 10^{3} / \mathrm{mm}^{3}$ & $7 \pm 2.4$ & $6.8 \pm 1.7$ & 0.3 & $7.1 \pm 1.8$ & $6.7 \pm 2.1$ & 0.2 \\
\hline $\mathrm{Hb}$ & $13.8 \pm 1.6$ & $12.5 \pm 1.2$ & $<0.001$ & $13 \pm 1.9$ & $12.4 \pm 1.5$ & 0.008 \\
\hline platelets $\times 10^{3} / \mathrm{mm}^{3}$ & $251.5 \pm 58$ & $265 \pm 72$ & 0.05 & $199 \pm 80$ & $215 \pm 67$ & 0.08 \\
\hline INR & $1 \pm 0.09$ & $1 \pm 0.09$ & 0.3 & 1.12 & 1.16 & 0.1 \\
\hline Creatinine & $0.87 \pm 0.2$ & $0.85 \pm 0.15$ & 0.6 & $0.8 \pm 0.1$ & $0.9 \pm 0.1$ & 0.8 \\
\hline
\end{tabular}

At baseline, AST and ALT of all included patients were elevated $48 \pm 30$ (IU/L) and $53 \pm 40$ (IU/L), respectively, while other liver function tests were normal (Table 2).

\section{Changes at the time of follow-up Laboratory}

In both groups, improvement of ALT $(53 \pm 42$ vs $21 \pm$ $10)$ and ( $55 \pm 37$ vs $26 \pm 11(p<0.01)$ as well as AST $(42 \pm$ 30 vs $24 \pm 10)$ and $(58 \pm 26$ vs $28 \pm 11)(p<0.01)$ were reported for early and advanced fibrosis stages, respectively. No significant changes of LFTs (total bilirubin, albumin, and INR) were found in both groups. The platelet count improved in both groups, but the increase was statistically significant only in the early fibrosis group ( $251.5 \pm 57$ vs $266 \pm 72, p=0.001)$ and not the advanced group ( $199 \pm 80$ vs $215 \pm 67, p=0.08)$. However, most patients at advanced fibrosis stages (12 out of 16) who had thrombocytopenia at baseline showed an improvement $($ mean $=124$ vs 188$)$ (Table 3$)$.

\section{Analysis of changes in FIB4, APRI, and LSM in both groups Non-invasive biomarkers}

Early fibrosis stages APRI score significantly decreased at follow-up compared to baseline $(0.42 \pm 0.3$ vs $0.24 \pm 0.1$, $p<0.01)$, while non-significant improvement was reported in Fib4 $1 \pm 0.6$ vs $0.93 \pm 0.5, p=0.1$ ) (Table 3 ). The change in APRI is correlated with that of FIB4 $(p=0.000)$ but not with the change in LSM (Table 4).

Advanced fibrosis stages APRI and Fib4 score significantly decreased at follow-up compared to baseline $(0.85$ \pm 0.5 vs $0.4 \pm 0.2, p<0.001)$ and $(2.9 \pm 2.3$ vs $1.8 \pm 1.4, p<$ 0.02 ), respectively (Table 3 ). The change in APRI correlated with that of FIB4 $(p=0.000)$ but not with the change in LSM (Table 4).

In all included patients, the percent of change of APRI is correlated with that of AST and ALT, and the percent of change of Fib4 is correlated with AST (Table 5).

Table 4 Correlation between change in APRI, FIB4, and LSM

\begin{tabular}{|c|c|c|c|c|c|c|c|c|c|c|c|c|}
\hline & \multicolumn{6}{|c|}{ Early stage } & \multicolumn{6}{|c|}{ Advanced stage } \\
\hline & \multicolumn{2}{|c|}{ APRI diff } & \multicolumn{2}{|c|}{ Fib4 diff } & \multicolumn{2}{|c|}{ Stiffness diff } & \multicolumn{2}{|c|}{ APRI diff } & \multicolumn{2}{|c|}{ Fib4 diff } & \multicolumn{2}{|c|}{ Stiffness diff } \\
\hline & $r$ & $P$ value & $r$ & $P$ value & $r$ & $P$ value & $r$ & $P$ value & $r$ & $P$ value & $r$ & $P$ value \\
\hline APRI diff & & & 0.677 & 0.000 & 0.105 & 0.4 & & & 0.706 & 0.000 & -0.148 & 0.4 \\
\hline Fib4 diff & 0.677 & 0.000 & & & 0.086 & 0.5 & 0.7 & 0.000 & & & 0.001 & 0.1 \\
\hline Stiffness diff & 0.105 & 0.413 & 0.086 & 0.505 & & & -0.148 & 0.381 & 0.001 & 0.993 & & \\
\hline
\end{tabular}


Table 5 Correlation between the percentage of change of liver enzymes and fibrosis scores

\begin{tabular}{|c|c|c|c|c|c|c|c|c|c|c|}
\hline & \multicolumn{10}{|c|}{ Percent of change } \\
\hline & \multicolumn{2}{|c|}{ STIFFNESS } & \multicolumn{2}{|c|}{ ALT (IU/L) } & \multicolumn{2}{|c|}{ AST (IU/L) } & \multicolumn{2}{|c|}{ APRI score } & \multicolumn{2}{|c|}{ Fib4 calculation } \\
\hline & $r$ & $P$ value & $r$ & $P$ value & $r$ & $P$ value & $r$ & $P$ value & $r$ & $P$ value \\
\hline STIFFNESS & & & -0.084 & 0.408 & -0.031 & 0.758 & 0.037 & 0.715 & 0.095 & 0.347 \\
\hline ALT (IU/L) & -0.084 & 0.408 & & & 0.394 & 0.000 & 0.373 & 0.000 & -0.069 & 0.494 \\
\hline AST (IU/L) & -0.031 & 0.758 & 0.394 & 0.000 & & & 0.820 & 0.000 & 0.678 & 0.000 \\
\hline APRI score & 0.037 & 0.715 & 0.373 & 0.000 & 0.820 & 0.000 & & & 0.743 & 0.000 \\
\hline Fib4 Calculation & 0.095 & 0.347 & -0.069 & 0.494 & 0.678 & 0.000 & 0.743 & 0.000 & & \\
\hline
\end{tabular}

\section{Transient elastography in early and advanced stages at baseline and follow-up}

Early stages LSM markedly improved at the time of follow-up (5.9 \pm 1.5 vs $5.4 \pm 2.2 \mathrm{Kpcal}, p=0.04$ ) (Table 3 ).

Subgroup analysis revealed that LSM significantly decreased in patients classified as $\mathrm{F} 1$ at baseline $(6 \pm 0.4$ vs $5 \pm 1.2, p<0.001)$ (Table 6).

Advanced stages LSM improved at the time of followup, but was statistically insignificant $(18 \pm 8.8$ vs $15.9 \pm$ $7.8 \mathrm{Kpcal}, p=0.07$ ) (Table 3); however, subgroup analysis demonstrated a significant decrease of LSM in patients classified as F3 at baseline $(11.1 \pm 0.8$ vs $8.5 \pm 2 \mathrm{Kpcal}, p=$ 0.02) (Table 6).

In all included patients, the percent of change of LSM was not correlated with either AST nor ALT (Table 5).

The distribution of fibrosis stages among the studied patients at baseline and follow-up

The percentage of patients stratified as early fibrosis stages significantly increased at follow-up compared to baseline $(p<0.001)$ (Fig. 1).

\section{Comparison between the two groups regarding the degree of change in stiffness score}

Although the amount of change was bigger in advanced than early fibrosis stages, the difference was statistically insignificant $(p$ value $=0.1)$ (Fig. 2$)$.

\section{Baseline factors affecting fibrosis scores at a long-term follow-up (Table 7)}

Baseline FIB4 and liver stiffness measured by fibroscan are the main determinants of fibrosis at the time of follow-up regardless of age, BMI, and existence of diabetes. For patients with high FIB4 and LS before treatment, their scores will remain high in a long term.

\section{Discussion}

A long-term follow-up of $\mathrm{CHCV}$ patients after being successfully treated with DAAS should be directed to selected patients who still have the risk to develop hepatic complications in spite of achieving SVR. As posttreatment prognosis is mainly determined by the fibrosis stage, many studies have been conducted to evaluate whether regression of fibrosis can be achieved after completion of DAAS therapy; however, most of these studies were done at a short duration after the end of treatment (12 and 24 weeks ) [14, 15]. Additionally, the selection of the most reliable method to categorize the fibrosis stage in treated patients would help clinicians to identify those needing regular medical care and HCC surveillance.

In our study, patients were recruited at an average of 16 months after the end of DAAs and classified according to TE done before treatment initiation into 2 groups early and advanced fibrosis. LSM decreased in both early and advanced fibrosis groups $(5.9 \pm 1.5$ vs $5.4 \pm 2.2 \mathrm{Kpcal}$ and $18.8 \pm 8.8$ vs $15.9 \pm 7.8 \mathrm{Kpcal}$, respectively).

Our results agree with those of a study that evaluated the long-term changes of liver elasticity in $143 \mathrm{CHCV}$ patients who achieved SVR by DAAs [16], where LSM

Table 6 Subgroup analysis of changes in fibrosis scores

\begin{tabular}{|c|c|c|c|c|c|c|c|c|c|}
\hline \multirow{2}{*}{$\begin{array}{l}\text { Baseline } \\
\text { TE }\end{array}$} & \multicolumn{3}{|l|}{ LSM } & \multicolumn{3}{|l|}{ APRI } & \multicolumn{3}{|l|}{ FIB4 } \\
\hline & Baseline & Follow-up & $P$ value & Baseline & Follow-up & $P$ value & Baseline & Follow-up & $P$ value \\
\hline F0 & $4.34 \pm 0.7$ & $5.05 \pm 2.4$ & 0.19 & $0.46 \pm 0.34$ & $0.24 \pm 0.13$ & 0.004 & $1 \pm 0.6$ & $0.9 \pm 0.6$ & 0.5 \\
\hline$F 1$ & $6 \pm 0.4$ & $5 \pm 1.2$ & $<0.001$ & $0.4 \pm 0.3$ & $0.26 \pm 0.1$ & 0.006 & $1.1 \pm 0.8$ & $0.98 \pm 0.5$ & 0.37 \\
\hline$F 2$ & $8.1 \pm 0.8$ & $6.9 \pm 3$ & 0.15 & $0.48 \pm 0.2$ & $0.2 \pm 0.1$ & 0.001 & $1.15 \pm 0.5$ & $0.95 \pm 0.5$ & 0.13 \\
\hline F3 & $11 \pm 0.8$ & $8.5 \pm 2$ & 0.02 & $0.78 \pm 0.7$ & $0.3 \pm 0.1$ & 0.06 & $1.47 \pm 0.8$ & $0.95 \pm 0.4$ & 0.08 \\
\hline $\mathrm{F} 4$ & $21 \pm 8.6$ & $18.5 \pm 7.5$ & 0.14 & $0.86 \pm 0.5$ & $0.4 \pm 0.25$ & $<0.001$ & $3.3 \pm 2.5$ & $2 \pm 1.5$ & 0.01 \\
\hline
\end{tabular}




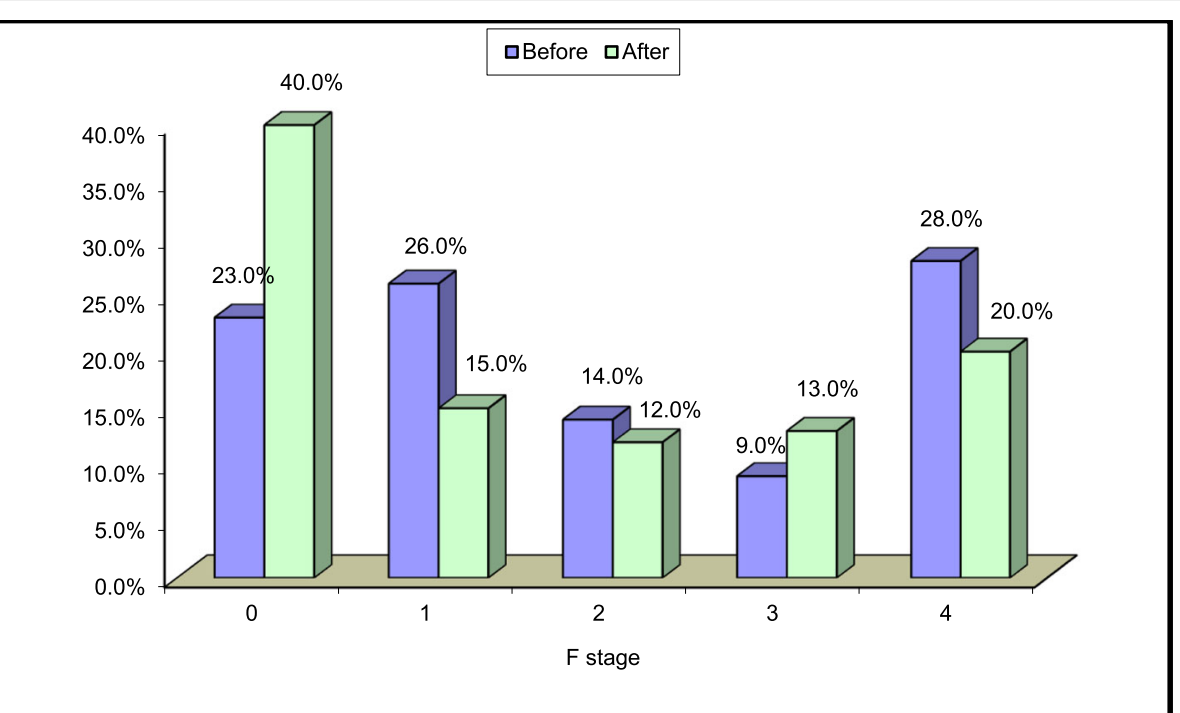

Fig. 1 Comparison of distribution of fibrosis stages among the studied patients at baseline and follow up: difference was statistically significant $(<0.001)$

improved significantly in cirrhotic and non-cirrhotic patients 25.9 vs $14.5 \mathrm{Kpcal}$ and 7.8 vs $5.4 \mathrm{Kpcal}$, respectively, at week 96 post-treatment. In the same study, it was reported that patients with early compensated cirrhosis (baseline LSM=20.4pkcal) had significant progressive improvement of LSM at 6 and 24 months ((14.8 Kpcal and $11.2 \mathrm{Kpcal})$, respectively, while patients at more advanced cirrhosis stage denoted by impaired liver function with baseline LSM=32.6pkcal initially achieved a significant decrease in LSM at week 24 post-treatment that was not significantly sustained at week 96 (24 months) after treatment (22.7 vs $19.1 \mathrm{Kpcal})$. Finally, the change was significantly greater in the cirrhotic group given that they had higher readings at baseline, and

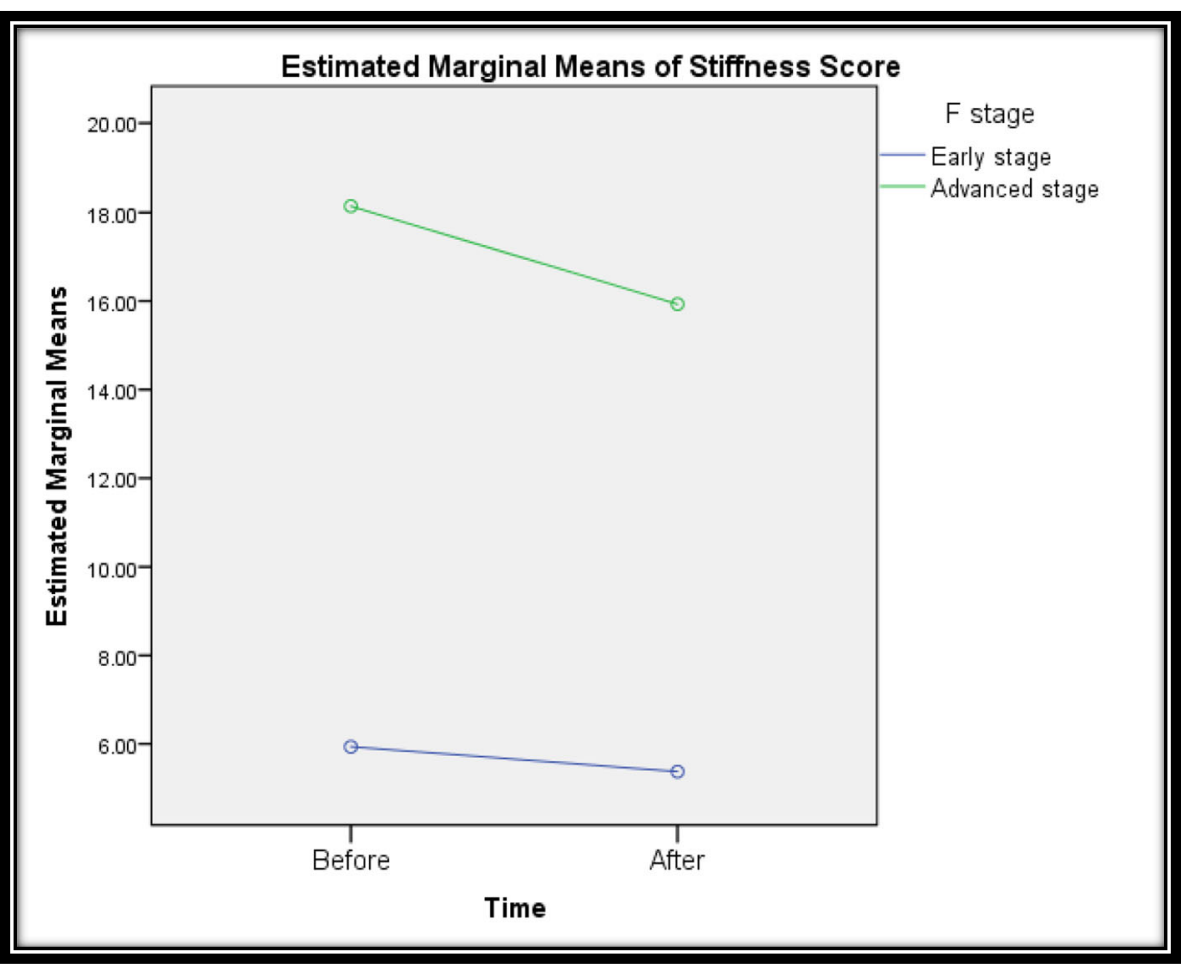

Fig. 2 Estimated marginal means of stiffness score in the early and advanced fibrosis groups 
Table 7 Regression analysis for baseline factors affecting stiffness score after treatment

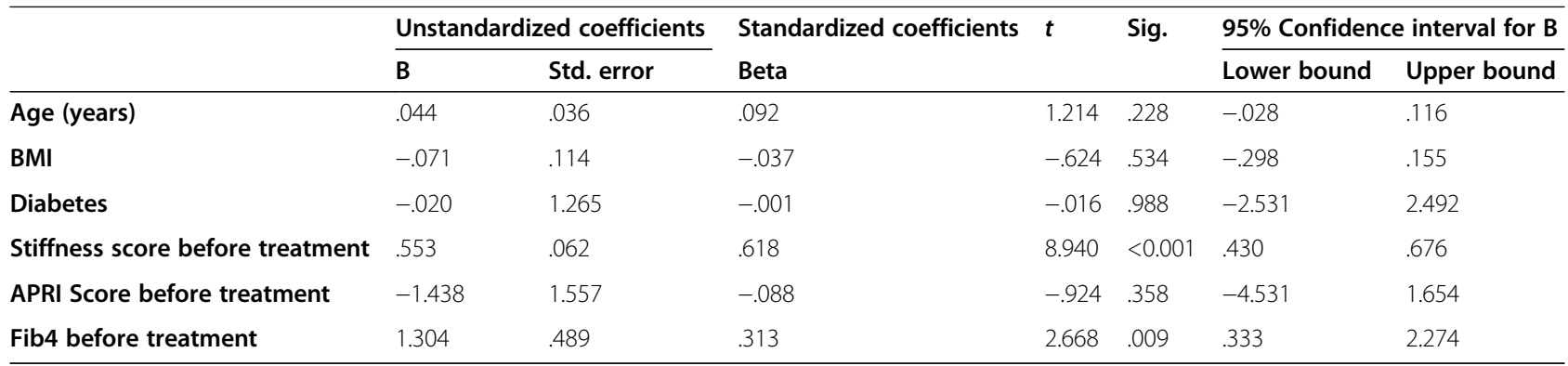

similarly in our study, the amount of change of LSM was bigger in advanced than early fibrosis stages. A meta-analysis attributed the higher decline of liver stiffness in advanced stages after antiviral therapy to a higher inflammatory burden, in which patients with high baseline ALT also showed a higher magnitude of the decline in LSM [17].

In the present study, the subgroup analysis showed that the significant reduction of LSM was reported in patients classified as F1 and F3 $(6.1 \pm 0.4$ vs $5 \pm 1.2, p=$ 0.001 and $11.1 \pm 0.8$ vs $8.5 \pm 2 \mathrm{Kpcal}, p<0.02)$. Subsidence of necro-inflammatory reaction is most likely responsible for the improvement reported in early stages [5]. As regards the advanced group, F3 is characterized histologically by numerous immature septae and bridges that precedes nodular formation characteristic of cirrhosis (F4) [18], after withdrawal of the insulting agent (HCV) immature septae might reverse, while mature crosslinked septae rich in elastin and associated with matrix modification are more likely to persist [19].

Clinically elevated liver enzymes are a marker of necro-inflammatory reaction, and in our study, AST and ALT significantly declined and were normalized at follow-up. Also, the non-invasive fibrosis serum biomarker of APRI significantly decreased in both groups and a marked reduction of Fib4 was recorded in advanced stages. The percent of change of APRI is correlated with that of AST and ALT, and the percent of change of Fib4 is correlated with AST; therefore, this improvement of serum biomarkers might be due to normalization of liver enzymes only and not representing fibrosis regression, especially that our results showed that the percent of change of liver stiffness is not correlated with that of liver enzymes, APRI, or Fib4.

Therefore, we could suggest that TE is the reliable method for evaluation of significant fibrosis in the context of follow-up after HCV treatment because as explained above, it is not affected by changes in liver enzymes and also we found that baseline TE scores is the main determinant of liver stiffness at follow-up which means that high scores before treatment are likely to persist after treatment even if a decline was achieved.
Additionally, patients in the advanced fibrosis group at follow-up recorded APRI score of $0.4 \pm 0.2$ which is lower than the validated cut-off value for significant fibrosis (0.77 and 0.83) [8], and also, the recorded Fib4 for the same group (1.8) is indeterminate [8] for the fibrosis stage.

In a prospective study designed to identify factors influencing fibrosis regression after DAAs, baseline BMI, steatosis, and hepatic stiffness were documented as independent factors [20]; this partially agrees with our study in which baseline LSM but not BMI affected LSM at follow-up; however, in another meta-analysis, BMI was not found to affect change in stiffness [17].

Importantly, LSM of $15.8 \mathrm{Kpcal}$ that was recorded in our advanced group patients alarms us that they are still at an increased risk to develop HCC. As evidenced by a study done by Pons et al. [21] , in which LSM $<10 \mathrm{Kpcal}$ at follow-up is correlated with a lower risk of HCC than the higher score of 10-20 Kpcal. He documented that the higher the LSM at follow-up, the greater the risk of HCC.

\section{Conclusion}

Although the scores of non-invasive methods of fibrosis assessment (TE, APRI, and FIB4) may improve after successful treatment of CHCV by DAAs, liver stiffness persists high in patients with pre-treatment advanced fibrosis stages. We recommend that TE should be done at least once after treatment to evaluate the further plan of follow-up especially if it is not done before treatment.

The limitations of the current study are the small number of patients specifically those included in the advanced stage group.

\section{Abbreviations}

CHCV: Chronic hepatitis C virus; TE: Transient elastography; LS: Liver stiffness; LSM: Liver stiffness measurement; Kpcal: Kilopascal; BMl: Body mass index;

LFT: Liver function tests; HCC: Hepatocellular carcinoma

\section{Acknowledgements}

Nurse Staff at Ain Shams University Viral hepatitis unit

Authors' contributions

Dr. NA and Dr. OA created the conception and design of the study: Dr. AM, M.S, and D.K were responsible for the acquisition of laboratory and clinical 
data. Data analysis and/interpretation were done by Dr. A.F. Drafting and revision of the manuscript were done by Dr. A.M, D.K, and A. F. The authors have read and approved the manuscript.

\section{Funding}

None was received.

\section{Availability of data and materials}

The datasets used and/or analyzed during the current study are available from the corresponding author on a reasonable request.

\section{Declarations}

\section{Ethics approval and consent to participate}

This study was approved by the research ethical committee at Ain Shams University, Faculty of Medicine, MS 124/2020. Verbal and written consent was taken from all participants before inclusion after approval of the research ethical committee at Ain Shams University.

\section{Consent for publication}

Not applicable

\section{Competing interests}

The authors declare that they have no competing interests.

\section{Author details}

${ }^{1}$ Tropical Medicine Department, Faculty of Medicine, Ain Shams University, 38 Abbassia street, Postal code, Cairo 1181, Egypt. ${ }^{2}$ Internal Medicine Department, Faculty of Medicine, Ain Shams University, Cairo, Egypt.

Received: 17 April 2021 Accepted: 19 August 2021

Published online: 28 August 2021

\section{References}

1. Sievert W, Altraif I, Razavi HA, Abdo A, Ahmed EA, Alomair A et al (2011) A systematic review of hepatitis C virus epidemiology in Asia, Australia and Egypt. Liver Int 31(Suppl 2):61-80

2. Dash S, Aydin Y, Widmer KE, Nayak L (2020) Hepatocellular carcinoma mechanisms associated with chronic HCV infection and the impact of direct-acting antiviral treatment. J Hepatocell Carcinoma 15(7):45-76

3. Lombardi A, Mondelli MU (2019) Hepatitis C: is eradication possible? Liver Int 39(3):416-426

4. Rout G, Nayak B, Patel AH, Gunjan D, Singh V, Kedia S, Shalimar (2019) Therapy with oral directly acting agents in hepatitis $C$ infection is associated with reduction in fibrosis and increase in hepatic steatosis on transient elastography. J Clin Exp Hepatol. 9(2):207-214. https://doi.org/10.1016/j. jceh.2018.06.009

5. Sepulveda-Crespo D, Resino S, Martinez I (2021) Strategies targeting the innate immune response for the treatment of hepatitis $C$ virusassociated liver fibrosis. Drugs 81(4):419-443. https://doi.org/10.1007/s4 0265-020-01458-x

6. Singal AG, Lim JK, Kanwal F (2019) AGA clinical practice update on interaction between oral direct-acting antivirals for chronic hepatitis $C$ infection and hepatocellular carcinoma: expert review. Gastroenterology. 156(8):2149-2157. https://doi.org/10.1053/j.gastro.2019.02.046

7. El-Garem H, Abd-Allah M, Omar H, Cordie A, Abdel Alem S, Mohey Eldin Elzahry MA, Ghaith D, Abou El-Soud NH, Kamal W, Elsharkawy A, Esmat G (2019) DAAs therapy associated with improved hepatic fibrosis in HCV-GT4 patients co-infected with HIV. Expert Rev Gastroenterol Hepatol. 13(7):693698. https://doi.org/10.1080/17474124.2019.1614441

8. European Association for Study of Liver; Association Latino Americana para el Estudio del Higado. EASL-ALEH Clinical Practice Guidelines (2015) Noninvasive tests for evaluation of liver disease severity and prognosis. Hepatol. 63(1):237-264

9. El Kassas M, Alboraie M, Omran D, Salaheldin M, Wifi MN, ElBadry M et a (2018) An account of the real-life hepatitis $C$ management in a single specialized viral hepatitis treatment centre in Egypt: results of treating 7042 patients with 7 different direct acting antiviral regimens. Expert Rev Gastroenterol Hepatol. 12(12):1265-1272. https://doi.org/10.1080/17474124.2 018.1476137
10. Waked I, Esmat G, Elsharkawy A, El-Serafy M, Abdel-Razek W, Ghalab R et al (2020) Screening and treatment program to eliminate hepatitis C in Egypt. N Engl J Med 382(12):1166-1174

11. Castera L, Forns $X$, Alberti A (2008) Non-invasive evaluation of liver fibrosis using transient elastography. J Hepatol 48(5):835-847. https://doi.org/10.101 6/j.jhep.2008.02.008

12. Wai CT, Greenson JK, Fontana RJ, Kalbfleisch JD, Marrero JA, Conjeevaram HS, Lok AS (2003) A simple noninvasive index can predict both significant fibrosis and cirrhosis in patients with chronic hepatitis C. Hepatology 38(2): 518-526. https://doi.org/10.1053/jhep.2003.50346

13. Sterling RK, Lissen E, Clumeck N, Sola R, Correa MC, Montaner J, S. Sulkowski M, Torriani FJ, Dieterich DT, Thomas DL, Messinger D, Nelson M, APRICOT Clinical Investigators (2006) APRICOT Clinical Investigators. Development of a simple noninvasive index to predict significant fibrosis in patients with HIV/HCV coinfection. Hepatology. 43(6):1317-1325. https://doi.org/10.1002/ hep. 21178

14. Elsharkawy A, Alem SA, Fouad R, El Raziky M, El Akel W, Abdo M et al (2006) Changes in liver stiffness measurements and fibrosis scores following sofosbuvir based treatment regimens without interferon. J Gastroenterol Hepatol 32(9):1624-1630

15. Knop V, Mauss S, Goeser T, Geier A, Zimmermann T, Herzer K, Postel N, Friedrich-Rust M, Hofmann WP, German Hepatitis C-Registry, Ende K, Pathil A, Bauer T, Zeuzem S, Berg T, Cornberg M, Börner N, Ringelhan M, Klinker H, Schlenker T, Lutz T, Heinzow H, Günther R, Busch H, Baumgarten A, Buggisch P, Roessle M, Hüppe D, Manns MP, Niederau C, Sarrazin C, Schirmacher P, Simon KG, Wedemeyer H (2020) Dynamics of liver stiffness by transient elastography in patients with chronic hepatitis $C$ virus infection receiving direct-acting antiviral therapy-results from the German Hepatitis CRegistry. J Viral Hepat. 27(7):690-698. https://doi.org/10.1111/jvh.13280

16. Pietsch V, Deterding K, Attia D, Ringe Kl, Heidrich B, Cornberg M, Gebel M, Manns MP, Wedemeyer H, Potthoff A (2018) Long-term changes in liver elasticity in hepatitis $C$ virus-infected patients with sustained virologic response after treatment with direct-acting antivirals. United European Gastroenterol J. 6(8):1188-1198. https://doi.org/10.1177/2050640618786067

17. Singh S, Facciorusso A, Loomba R, Falck-Ytter YT (2018) Magnitude and kinetics of decrease in liver stiffness after anti-viral therapy in patients with chronic hepatitis C: a systematic review and meta-analysis. Clin Gastroenterol Hepatol 16(1):27-38.e4

18. Goodman ZD (2007) Grading and staging systems for inflammation and fibrosis in chronic liver diseases. J Hepatol 47(4):598-607

19. Garcia-Tsao G, Friedman S, Iredale J, Pinzani M (2010) Now there are many (stages) where before there was one: in search of a pathophysiological classification of cirrhosis. Hepatology. 51(4):1445-1449. https://doi.org/10.1 002/hep. 23478

20. Soliman H, Ziada D, Salama M, Hamisa M, Badawi R, Hawash N, Selim A, Abd-Elsalam S (2020) Predictors for fibrosis regression in chronic HCV patients after the treatment with DAAS: results of a real-world cohort study. Endocr Metab Immune Disord Drug Targets. 20(1):104-111. https://doi.org/1 $0.2174 / 1871530319666190826150344$

21. Pons M, Rodríguez-Tajes S, Esteban Jl, Mariño Z, Vargas V, Lens S, Buti M, Augustin S, Forns X, Mínguez B, Genescà J (2020) Non-invasive prediction of liver-related events in patients with HCV-associated compensated advanced chronic liver disease after oral antivirals. J Hepatol. 72(3):472-480. https:// doi.org/10.1016/j.jhep.2019.10.005

\section{Publisher's Note}

Springer Nature remains neutral with regard to jurisdictional claims in published maps and institutional affiliations. 